\title{
Australian internet policy
}

\section{Angela Daly}

Faculty of Law, Queensland University of Technology, Australia, angela.daly@qut.edu.au

\section{Julian Thomas}

Social Change Research Platform, RMIT University, Melbourne, Australia, julian.thomas@rmit.edu.au

Published on 14 Mar 2017 | DOI: 10.14763/2017.1.457

\begin{abstract}
This special issue focussing on internet policy in Australia provides a snapshot of developments on various topics (access, privacy, censorship) as a means of understanding better the state of play in Australia, and also how this compares to internet policy in other parts of the world, especially Europe and North America. Given changing geopolitics, the influence of internet policy in the rest of the Asia Pacific through vehicles such as the Regional Comprehensive Economic Partnership (RCEP) may become increasingly important in Australia in the coming years. This leaves Australia, and its internet policy, at a crossroads, which may reflect broader dynamics in internet policy internationally, and makes this an interesting time in which to explore what is happening in this particular country.
\end{abstract}

Keywords: Australia, Internet policy, Privacy

\section{Article information}

Received: 05 Mar 2017 Reviewed: 09 Mar 2017 Published: 14 Mar 2017

Licence: Creative Commons Attribution 3.0 Germany

Competing interests: The author has declared that no competing interests exist that have influenced the text.

URL: http://policyreview.info/articles/analysis/australian-internet-policy

Citation: Daly, A. \& Thomas, J. (2017). Australian internet policy. Internet Policy Review, 6(1). https://doi.org/10.14763/2017.1.457 


\section{PAPERS IN THIS SPECIAL ISSUE}

Introducing Australian internet policy: problems and prospects

Angela Daly, Queensland University of Technology, Australia

Julian Thomas, RMIT University, Australia

The passage of Australia's data retention regime: national security, human rights, and media scrutiny

Nicolas Suzor, Queensland University of Technology, Australia

Kylie Pappalardo, Queensland University of Technology, Australia

Natalie McIntosh, Queensland University of Technology, Australia

Computer network operations and 'rule-with-law' in Australia

Adam Molnar, Deakin University, Australia

Christopher Parsons, Citizen Lab, Canada

Erik Zouave, KU Leuven, Belgium

Internet accessibility and disability policy: lessons for digital inclusion and equality from Australia

Gerard Goggin, University of Sydney, Australia

Scott Hollier, Media Access Australia, Australia

Wayne Hawkins, Australian Communications Consumer Action Network (ACCAN), Australia

Internet policy and Australia's Northern Territory Intervention

Ellie Rennie, Swinburne University of Technology, Australia

Jake Goldenfein, Swinburne University of Technology, Australia

Julian Thomas, RMIT University, Australia

Towards responsive regulation of the Internet of Things: Australian perspectives

Megan Richardson, The University of Melbourne, Australia

Rachelle Bosua, The University of Melbourne, Australia

Karin Clark, The University of Melbourne, Australia

Jeb Webb, The University of Melbourne, Australia

Atif Ahmad, The University of Melbourne, Australia

Sean Maynard, The University of Melbourne, Australia

\section{INTRODUCING AUSTRALIAN INTERNET POLICY: PROBLEMS AND PROSPECTS}

\section{INTRODUCTION}

We are delighted to introduce this special edition of the Internet Policy Review on Australian Internet Policy. This is the first special edition to focus explicitly on a country or region outside of the journal's Europe focus - although there have been previous special issues and individual articles which have in practice ventured beyond the continent's confines. We also believe that this is the first time that a special edition of an international journal has addressed Australian 
internet policy in a way which is relevant to internal Australian, as well as transnational, discussions of these matters. Accordingly, it is our hope that this special issue will be useful both for domestic audiences considering the current state of Australian internet policy and the scope for possible future directions and reforms, and also as a point of comparison for international audiences, in order to understand how this far-flung country is addressing issues familiar to all countries, and issues related to its specific national characteristics.

The internet took its first breath in Australia in 1989, when a connection was established between a computer at the University of Melbourne and the University of Hawaii, using a 56 Kbps satellite link (Clarke, 2004; Given \& Goggin, 2012). From those origins in academic communications, the internet has rapidly become a basic element in everyday social and economic life. Australians are enthusiastic and intensive users of digital communications technologies. The Pew Research Center's 2016 global survey data reports that, after South Korea, Australia now has the second highest rate of internet uptake in the world, with $93 \%$ of the adult population using the net, and the second highest rate of smartphone ownership, at $77 \%$ of the adult population (Pew, 2016). Australians were also avid early online shoppers; yet Australia was also described in 2014 - by the nation's own Attorney-General - as "the worst offender of any country in the world when it comes to piracy" (Hopewell, 2014).

Australia can also claim a distinctive and significant place in the development of internet infrastructures. Today's ubiquitous Wi-Fi networks rely heavily on Australian innovations in wireless networks, derived from public sector research in radio astronomy in the 1990s (CSIRO, 2016). In relation to internet access networks, Australia's publicly-funded National Broadband Network (NBN) has a striking geographical reach and policy ambition in comparison with international models. The NBN, now due for completion in 2020, aims to provide fast internet even to the most remote parts of the continent, and to foster innovation and competition in the sector. In its early phase of design and planning, the NBN was perceived to be visionary: a bold combination of communications policy and micro-economic reform. While it has without question already substantially improved access and infrastructure for many Australians, the NBN's convoluted path through political contention and delay is likely to provide many lessons for future scholars and practitioners of internet policy. Even so, the NBN remains one key example of the occasional propensity in Australia to approach communications (and other policy domains) not only through incremental, pragmatic responses to immediate problems, but also through far-reaching, very ambitious, 'nation building' schemes.

Due to particular, geographic, political and economic issues, Australian communications policy, and then internet policy, have been shaped by certain country-specific controversies. Policy has been shaped by the distinctive challenges of geography - a large country, with a small population, most of which is highly urbanised - and political economy, where the federal structure of national government demands a high level of subsidy for services to Australia's expansive rural and remote areas. Despite the high levels of use, digital exclusion remains a highly visible problem for governments, especially in Australia's regions. The Australian government has now moved to an ambitious 'digital first' strategy where service development and delivery is focussed on online platforms. But a substantial number of the very citizens who depend most on government services are not currently able to access them. A recent study reported wide variations in the degree of access and in digital skills and capabilities, especially between Australia's capital cities and some regional areas. Further, measures of the affordability of internet access suggested that this declined in the 2014-2016 period, as Australians increased the proportion of their incomes applied to paying for this service (Thomas et al., 2016). However, perhaps as an unintended consequence of the long focus on the NBN, plans to address 
digital inclusion issues are not yet as advanced as in other jurisdictions. Australia at this stage has no equivalent to the United Kingdom's 2014 digital inclusion strategy.

Access and infrastructure have been by no means the only areas of debate or scholarly attention and concern. Recent developments have highlighted weak privacy protections, and ongoing battles between large copyright holders and internet service providers over filesharing are not yet resolved. Regional and global geopolitical trends are now also influencing Australian internet policy, as trade in services and international data flows become increasingly controversial elements in global politics.

\section{Australia in a global context: tied to the West, turning to Asia}

As an economically advanced Western-style anglophone liberal democracy, Australia's law and politics have much in common with its counterparts in North America and Europe. Yet its geographical position in the Asia Pacific region, and 21st century 'pivot' to Asia (Australian government, 2012) place the country at a crossroads culturally, legally and politically. This dual nature of Australia can also be seen in internet policy developments, some of which will resonate with other Global North locations, while other developments may be more in keeping with its geographical neighbourhood.

One large point of divergence from the European context is human rights protection in Australia. In the absence of a comprehensive set of rights in either the Australian Constitution or legislation, Australia occupies a unique position as the only Western liberal democracy not to have the full suite of domestically-enforceable human rights, relying instead upon a patchwork of legislation, common law, and constitutional interpretation. The outcomes this produces can be seen in a number of internet policy areas, prominently privacy and free expression. While Australia participated in the shadowy Five Eyes surveillance partnership, there was no ability to challenge its practices on the basis of infringement of citizens' privacy rights, in sharp contrast to the situation in the European Union where the Snowden revelations triggered outcomes such as the invalidation of the Data Retention Directive (Digital Rights Ireland $v$ Minister for Communications, 2014) and the EU-US Safe Harbor agreement (Schrems $v$ Data Protection Commissioner). The lack of strong, constitutional privacy protections may prove to be an eyeopener for British readers faced with a Brexit situation which may involve the disapplication of EU law (and the Charter of Fundamental Rights) and an exit from the European Convention on Human Rights.

In Australia, the parliamentary process and common law rights have not proved sufficient so far to protect Australians' privacy rights. Proposals for strengthening privacy have been developed and discussed at length, but have not yet been translated into enforceable laws and norms (e.g. Australian Law Reform Commission, 2014). The coming into force of the EU's General Data Protection Regulation (GDPR) has sparked some debate in Australia about compliance with the extra-territorial reach of this law, since the GDPR applies to data processors and controllers outside of the EU which process the data of EU citizens (Shaw, 2015). Whether the GDPR, or other international provisions, can produce spillovers of higher privacy protection for Australians, remains to be seen.

The Australian experience with regional and bilateral trade agreements and their effect on internet matters may also prove instructive in the context of Brexit and other developments elsewhere, given the changes that implementation of the Australia-United States Free Trade 
Agreement (AUSFTA) required in Australian copyright law. Australia's Productivity Commission - a highly respected, independent economic policy advisory body - consider these to have had a detrimental effect in Australia (see Australian Government Productivity Commission, 2016). But in other respects the United States represents a policy road not chosen: for instance, in the context of debate about whether a broad 'fair use' exception to copyright should be introduced into Australian law. Despite many years of consideration including Australian Law Reform Commission and Productivity Commission recommendations that fair use become part of Australian law, this has not happened, and in fact faces strong resistance from certain rightsholders groups (Malcolm, 2017; Aufderheide \& Hunter Davis, 2017).

Australia has been the site of many digital copyright and piracy battles over recent years. This may be the result of its reputation as an unusually strong market for pirated media. The respected peer-to-peer news site TorrentFreak has often placed Australia at or near the top of its lists of torrenting countries for popular series such as Game of Thrones. Australia was the first jurisdiction internationally in which large copyright holders sued an internet service provider (ISP) for alleged copyright infringements carried out by its users, in the Roadshow $v$ iiNet saga, but the end result was a decision of the Australian High Court which found the ISP, iiNet, was not liable for its customers' conduct in these circumstances (Lindsay, 2012). Subsequent to this decision, the last five years has seen discussions between ISPs and rightsholders, and some government policy interventions, to address piracy concerns through measures including a graduated response scheme, but no agreement was reached on the allocation of costs and the scheme was recently abandoned (Francis, 2016). Yet on copyright infringement, Australia has also taken some negative cues from the United Kingdom, such as the site-blocking legislation introduced in 2015, which, like the UK scenario, has had limited effectiveness in addressing the downloading of copyright-infringing material (Dootson, Pappalardo, \& Suzor, 2016).

The international climate concerning trade has changed significantly since we began work on this special issue in March 2016. Issues related to intellectual property were prominent in public debate over the proposed, and highly controversial, Trans-Pacific Partnership (TPP) (Rimmer, 2017). The TPP's Intellectual Property and E-Commerce chapters would likely have had a significant effect on Australian internet policy (Daly, 2013). However, the TPP now appears doomed, with the new US president Donald J. Trump withdrawing his country from the treaty. But this does not necessarily spell the death knell for multilateral trade agreements more generally. Australia is still involved in negotiations for the Trade in Services Agreement (TiSA) which also concerns internet policy matters (Erickson \& Leggin, 2016). In the power vacuum left by the US, China has stepped into the Asia Pacific region by spearheading the nascent Regional Comprehensive Economic Partnership (RCEP) agreement negotiations (Jaipragas, 2017). Whether these negotiations actually result in finalised agreements is unclear, but the international trade space in the coming years may end up taking on a more European or Chinese character, with significant implications for internet policy in other countries in the region, including Australia.

There are some internet policy issues which have been prominent in the rest of the world but have received scant attention so far in Australia. One such matter is network neutrality. This has been a major topic for discussion in many parts of the world, including the US, the European Union, Brazil and India, which have all introduced regulation to address concerns about internet service providers engaging in discriminatory traffic practices (Marsden, 2017). Yet in Australia there has been very limited discussion on the matter (Daly, 2016a). The reason for this is likely to be Australia's distinctive market structure for internet service. The country has had 
historically low rates of uptake for cable or satellite television networks, especially in comparison with North America and Europe, and it is this industry sector which has sparked significant concern about neutrality elsewhere. Another factor is the increasingly significant role of the NBN as a publicly-owned, nation-wide, near-monopoly wholesaler of internet access. The intent here was that Telstra, Australia's dominant telecommunications firm, should no longer be conflicted as a major wholesaler and retailer of access. But neither of these points mean that neutrality will not become an important problem in the future, with the same dynamics of media convergence operating in Australian markets as elsewhere. In fact, one feature of the Australian market - the ubiquity of data caps for fixed as well as mobile internet access - may make the problem of neutrality more likely to arise, as streaming services begin to seek more concessional or 'uncapped' arrangements with particular ISPs.

Another matter is digital market dominance, or the emergence of monopolistic transnational internet companies and their economic and socio-political effects on internet users. Policy and regulatory attention has been paid to this issue in various parts of the world, particularly the EU (Daly, 2016b), but to date no action has been taken in Australia, notwithstanding (for instance) Google's 90\% market share of all searches in Australia (Scardamaglia \& Daly, 2016). Australia has, however, moved comparatively quickly in legislating to capture lost taxation revenue from transnational diverted profits, a problem particularly associated with internet businesses (Ting et al., 2016). These provisions are popularly known as the "Google Tax", although their impact on Google is not yet clear.

Looking to the future, an array of technological developments including the Internet of Things, artificial intelligence, robotics, cryptocurrency, and automation are all currently emerging as areas likely to further extend current discussions of privacy, security, intellectual property and competition in Australia.

\section{IN THIS ISSUE}

We are delighted to have five contributions on Australian internet policy issues for this special edition of the Internet Policy Review. The authors come from a variety of disciplines, including media and communications, cultural studies, law, criminology and, computing and information systems. We would like to thank all authors for their contributions, as well as the reviewers and Internet Policy Review editorial staff, without whom this special edition would not be possible.

Some of these papers, and the idea to have a journal special edition on Australian internet policy, emerged from a one-day conference hosted by Swinburne University of Technology in Melbourne on 5 October 2015, which was generously funded by the au Domain Administration (auDA) as an academic pre-event to that year's Australian Internet Governance Forum. We thank everyone at Swinburne (where we were both then based) and auDA for their support for that event, as well as for this special edition.

The papers in this special edition cover a range of areas of internet policy in Australia. One area which is under-represented is the relationship between the internet and intellectual property. During and immediately after the iiNet case discussed above, digital copyright and piracy were high priorities in Australian internet policy discussions. It seems that with the Snowden revelations of Australian participation in mass surveillance programmes, and subsequent introduction of mandatory data retention legislation, privacy and data protection have supplanted digital copyright as the current 'hot topic' in Australian internet policy, as attested by 
this special edition's articles. However, digital intellectual property issues have not gone away, and copyright and related concerns are likely to figure once more in future surveys of the topic.

Indeed, specifically on the topic of data retention, Suzor, Pappalardo, and McIntosh's contribution to this special edition analyses the media debate accompanying the introduction of data retention legislation in Australia in 2015. The legislation remains very problematic from a human rights perspective, especially its impact upon individual privacy. As the authors found, despite these public interest concerns featuring in media discussions of the legislation, they were largely unaddressed in the final text of the law. This represents a limitation on the ability of civil society to influence Australian law-making in a problematic context where there is no constitutional protection for privacy rights. This is an important article on a topic which continues to attract public debate in Australia, including, at the time of writing, around Australian government proposals to extend the use of retained data to civil proceedings, involving further privacy infringements and scope-creep (Cooper, 2017).

Issues of privacy are also explored in Molnar, Parsons, and Zouave's article on computer network operations (CNOs) in Australia. CNOs constitute government intrusion or interference with networked ICT infrastructures for the purposes of law enforcement and security intelligence. Several pieces of legislation authorise Australian government agencies to use CNOs for security and law enforcement purposes. However the authors identify the lack of safeguards and effective oversight of law enforcement and security activities in these laws, compounded by the secrecy accompanying most CNO measures in Australia, resulting in serious risks to democratic freedoms and also procedural justice. Again, the authors of this piece also point to the lack of comprehensive and enforceable human rights in Australia, observing how this is placing Australians - when faced with CNOs - in a weaker position compared to their counterparts in other Five Eyes countries. With the recent Wikileaks revelations about CNO use by the US CIA and its partners including the Australian intelligence agencies (Hern, 2017) on the one hand, and new plans to regulate the use of CNOs in Italy (Pietrosanti and Aterno, 2017) government hacking is a timely topic and this is an important contribution to its academic understanding in Australia and beyond.

Other contributions in this special edition explore the relationship between Australian internet policy, and other policy areas. Goggin, Hollier, and Hawkins examine the interaction of disability policy and internet access in Australia. Digital inclusion, especially for people with disabilities, has been a long-standing issue for internet policy internationally. Australia has had a relatively good track record historically in applying anti-discrimination law to web accessibility, but over the last fifteen years, progress in this area has been slower than expected. Yet, Australia's ambitious 'nation building projects' in the form of the National Broadband Network (NBN) and National Disability Insurance Scheme (NDIS) may go some way to remedying this lack of progress, and may also provide models that can be used in other countries to achieve these objectives.

The interaction of internet policy and Indigenous rights is explored in Rennie, Goldenfein, and Thomas' article, which focuses on the surveillance of publicly-funded computers and internet use in remote Indigenous communities during the Australian government's problematic and controversial Northern Territory 'Intervention', a broad cluster of legal and policy changes which from 2007 onwards had a major impact on social welfare, land tenure, law enforcement, and many other aspects of the Indigenous experience in more than 70 affected communities in outback Australia. As part of the intervention, between 2007 and 2012, providers of internet and computer access facilities were required to document the use of their computers, keep detailed 
records of computer users and instal filters on computers and networks - a form of official ICT surveillance, designed to target a particular group, Indigenous people. The authors argue that it was the digital divide between Indigenous and other Australians which made this form of targeted surveillance possible, and that in fact the policy exacerbated this divide by imposing costly requirements on those attempting to provide some level of internet access in remote communities. This article is an important contribution to the little-researched topic of Indigenous rights and technology in Australia, and demonstrates the limits of 'liberation technology' in contexts of intersectional disadvantage.

Looking to the future, the article from Richardson, Bosua, Clark, Webb, Ahmad, and Maynard explores the nascent Australian Internet of Things community and their experiences and concerns about privacy and data protection. The authors found that privacy continues to be valued by IoT users and they also want greater control and transparency regarding their IoT data, but their awareness of the current legal framework protecting personal information was low. In consequence, the authors suggest a 'responsive regulation' model for IoT governance incorporating privacy by design principles in order to respond better to the wishes of IoT users and developers, while not discounting that larger scale law reform in Australia may also be needed in the future to address concerns around IoT-enabled ubiquitous surveillance. This article, thus, demonstrates that privacy remains an important value in the digital age, despite a lack of constitutional protection in Australia.

\section{CONCLUSION}

The articles here cover a range of topics in Australian internet policy and, we hope, provide the reader with an introduction to developments in this country. This special issue, however, cannot provide a comprehensive picture. As we have noted, digital intellectual property issues are important, but are not explored here. Intersections with migration and refugee policy, and Australia's international relations are promising areas for investigation which are not covered in this issue. Internet governance, and Australia's role in international internet governance processes, as well as the administration of domain names, are also topics which merit further attention. To some degree these gaps reflect the wider state of the field. We do not yet have a comprehensive account of how the Australian government and other institutions have approached the regulation of the internet and understood its emergence as field of law and policy. In our view, Australia is still in the process of reaching robust policy positions on core internet policy problems such as intellectual property, privacy and surveillance. Australian internet policy researchers also have some way to go in documenting and assessing these developments.

In the articles collected here, privacy emerges as the most prominent theme. This is not because of any official current programme of law reform in this area; rather, it reflects the immediate needs of researchers responding to recent and current surveillance activities of diverse kinds, and a host of new technological developments. In Australia as elsewhere, privacy and security are likely to remain key concerns for work in the internet policy area, given ongoing debates around national security and data retention, the increasing use of drones and other automated vehicles, the growing importance of algorithmic media, and current developments in machine learning.

As the internet is already deeply embedded in everyday life and work, it is not surprising that internet policy now interacts with a plethora of other policy areas: in this special issue, the 
articles cover intersections with disability and Indigenous policy. Our attention to these points of connection is not only the result of the ubiquitous, essential character of internet service across diverse fields: it follows from Australia's deployment of far-reaching, major national policy programmes in these areas. In the case of the National Disability Insurance Scheme and the National Broadband Network, these ambitious developments have generated strong support across Australia's social and economic boundaries. In the case of the Northern Territory Intervention, promoted by government as a unifying, national response to a crisis in welfare, the intent and implementation of the policy remains controversial. We would suggest that all these initiatives point to a curiously double-edged quality in Australian public policy, which has strongly shaped the development of the internet in Australia. While much of what we see in Australian internet policy reveals a cautious, incremental and highly pragmatic approach, there remains a disposition towards far-reaching, highly ambitious, 'nation building' projects - and the results and ramifications of these are often surprising. 


\section{REFERENCES}

Aufderheide, P. \& Hunter Davis, D. (2017). Contributors and Arguments in Australian Policy Debates on Fair Use and Copyright: The Missing Discussion of the Creative Process.

International Journal of Communication, 11, 522-545.

Australian Government. (2012). Australia in the Asian Century. White Paper. Retrieved from

http://asialink.unimelb.edu.au/__data/assets/pdf_file/ooo4/645592/australia-in-the-asian-ce ntury-white-paper.pdf

Australian Government Productivity Commission. (2016). Intellectual Property Arrangements. Draft Report. Retrieved from

http://www.pc.gov.au/inquiries/completed/intellectual-property/draft/intellectual-property-ov erview-draft.pdf

Australian Law Reform Commission. (2014). Serious Invasions of Privacy in the Digital Era. ALRC Report 123. Retrieved from https://www.alrc.gov.au/publications/serious-invasionsprivacy-digital-era-alrc-report-123

Clarke, R. (2004). Origins and Nature of the Internet in Australia. Retrieved from www.rogerclarke.com/II/OzIo4.html.

Cooper, H. (2017). Data retention laws: Experts warn against opening up metadata to civil cases as telcos renew bid to change laws. Abc. Retrieved from

http://www.abc.net.au/news/2017-01-05/telco-industry-pushes-for-metadata-collection-chang es/8162896

CSIRO. (2016). Bringing WiFi to the world. Retrieved from

https://www.csiro.au/en/Research/D61/Areas/Wireless-

and-networks/Wireless-broadband/WiFi

Daly, A. (2013). The Trans-Pacific Partnership: a knockout blow for innovation? The Conversation. Retrieved from https://theconversation.com/the-trans-pacific-partnership-aknockout-blow-for-innovation-14262

Daly, A. (2016a). Net Neutrality in Australia: The Debate Continues, But No Policy in Sight. In L. Belli \& P. De Filippi (eds.). Net Neutrality Compendium: Human Rights, Free Competition and the Futures of the Internet. Springer.

Daly, A. (2016b). Private Power, Online Information Flows and EU Law: Mind the Gap. (Hart).

Digital Rights Ireland Ltd $v$ Minister for Communications, Marine and Natural Resources, No. C-293/12 and C-594/12 (Grand Chamber, European Court of Justice April 8, 2014). Retrieved from

http://eur-lex.europa.eu/legal-content/EN/TXT/HTML/?uri=CELEX:62012CJo293\&rid=1

Dootson, P., Pappalardo, K. \& Suzor, N. (2016). Blocking access to illegal file-share websites won't stop illegal downloading. The Conversation. Retrived from

https://theconversation.com/blocking-access-to-illegal-file-

share-websites-wont-stop-illegal-downloading-70473 
Erickson, M. \& Leggin, S. 2016. Exporting Internet Law through International Trade Agreements: Recalibrating U.S. Trade Policy in the Digital Age. Catholic University Journal of Law and Technology, 24(2), 317-368.

Francis, H. (2016). Foxtel and rights holders drop 'three strikes' piracy scheme. Sydney Morning Herald. Retrieved from

http://www.smh.com.au/technology/technology-news/foxtel-and-rights-holders-drop-three-str ikes-piracy-scheme-20160525-gp3b2y.html

Given, J \& Goggin, G. (2012) Australian Internet Histories: It's Time' Media International Australia, 143(1), 57-62.

Hern, A. (2017). Am I at risk of being hacked? What you need to know about the 'Vault 7 ' documents. The Guardian. Retrieved from

https://www.theguardian.com/technology/2017/mar/o8/wikileaks-vault-7-cia-documents-hac ked-what-you-need-to-know

Hopewell, L., (2014, January 2). Australia Worst In The World For Piracy, According To Our Attorney-General, Gizmodo. Retrieved from

www.gizmodo.com.au/2014/o6/australia-is-the-worst-in-the-world-for-piracy-according-to-att orney-general/

Jaipragas, B. (2017). As Trump kills the TPP, can China-backed RCEP fill the gap? South China Morning Post. Retrieved from

http://www.scmp.com/week-asia/geopolitics/article/2060041/trump-kills-tpp-can-china-back ed-rcep-fill-gap

Lindsay, D. (2012). ISP Liability for End-User Copyright Infringements: The High Court Decision in Roadshow Films v. iiNet. Telecommunications Journal of Australia, Volume 62, Number 4 .

Malcolm, J. (2017). Australia's Battle Over Fair Use Boils Over. Electronic Frontier Foundation DeepLinks Blog. Retrieved from https://www.eff.org/deeplinks/2017/o2/australias-battleover-fair-use-boils-over

Marsden, C. (2017). Network Neutrality: From Policy to Law to Regulation. Manchester University Press.

Pew Research Center (2016). "Smartphone Ownership and Internet Usage Continues to Climb in Emerging Economies". Retrieved from

http://www.pewglobal.org/files/2016/02/pew_research_center_global_technology_report_fin al_february_22_2016.pdf

Pietrosanti, F. \& Aterno, S. (2017). Italy unveils a legal proposal to regulate government hacking. Boing Boing. Retrieved from

http://boingboing.net/2017/02/15/title-italy-unveils-a-law-pro.html

Rimmer, M. (2017) The Trans-Pacific Partnership: Intellectual Property, Public Health, and Access to Essential Medicines. Intellectual Property Journal. Forthcoming.

Scardamaglia, A. \& Daly, A. (2016). Google, online search and consumer confusion in Australia. 
International Journal of Law and Information Technology, 24(3), 203-228.

Schrems v Data Protection Commissioner, Case C-362/14, CJEU, 6 October 2015.

Shaw, L. (2015). The impact of the new European General Data Protection Regulation in Australia. Keypoint Law. Retrieved from

http://www.keypointlaw.com.au/keynotes/impact-new-european-general-data-protection-regu lation-australia

Thomas, J., Barraket, J., Ewing, S., MacDonald, T., Mundell, M., and Tucker, J., (2016).

Measuring Digital Inclusion in Australia: The Australian Digital Inclusion Index, Swinburne University of Technology. Retrieved from https://digitalinclusionindex.org.au/the-indexreport/report/

Ting A, Faccio T and Kadet J. (2016). 'Effects of Australia's MAAL and DPT on Internet-Based Business', Tax Notes International, vol.83, pp. 145-51. 